\title{
Organization of treatment and orthodontic procedures

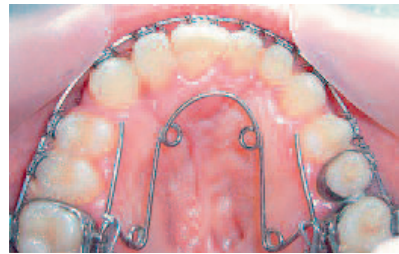 in cleft lip and palate rehabilitation
}

\author{
Olivier WEISSENBACH, Michel STRICKER, \\ Michel WEISSENBACH, Jean-Francois CHASSAGNE, \\ Etienne SIMON
}

\begin{abstract}
Only competent centres are able to provide the full range of multi-disciplinary specialized therapies that cleft lip and palate rehabilitation requires. Despite some detail differences in conducting treatment, the agreed centres produced consensual treatment philosophy and observe equivalent therapeutic schemes. These sequences, to which orthodontics invariably contributes, are designed to favour the normal outcome of facial development and functions.

Beginning early in mixed dentition, orthodontic rehabilitation is designed to afford patients good dental occlusion through orthopaedic and orthodontic therapies. At the end of the growth period, orthodontics prepares for eventual final surgical and prosthetic repair.

We avoid extraction of permanent teeth as an adjunct to treatment because it has deleterious effect on final skeletal harmony. We prefer basic appliances for mechanical therapy, and after completion of active treatment, a prolonged retention. A trained orthodontist is able to complete the orthopaedic and orthodontic stages in cleft lip and palate repair if he fully understands and follows the general cleft lip and palate treatment scheme and effectively communicates with the competent rehabilitation team.
\end{abstract}

\section{KEYWORDS}

Cleft lip and palate,

Orthopedic treatment,

Orthodontic treatment,

Therapeutic stages. 


\section{1 - INTRODUCTION}

Encumbered by many sequellae, the correction of cleft lip and palate (CLP) requires a multi-disciplinary treatment approach continued over a long period of time. Even though most orthodontists have scant experience in this type of collective therapy, some of them may be asked to use techniques with they are not familar to care for CLP patients.

The number of surgical interventions, the age at which they take place, and the choice of techniques define protocols that are usually the exclusive domain of teaching or surgical institutions ${ }^{14}$, a situation that may contribute to the hesitation orthodontists may express.
Orthodontists may also be disturbed by the great variety of approaches to CLP treatment that different competent centers adopt, at a time when science, especially the medical branch, is vigorously striving to make all therapy evidence based.

How should orthodontists take up their places as members of a CLP treatment team? How much time and effort will they have to devote to this collaboration? These are the questions we propose to answer in this article by stipulating the time demanded and the techniques required for performing the orthodontic component of the dento-facial rehabilitation the patient seek.

\section{2 - A BROAD SCHEDULE OF CLP INTERVENTION}

In order to help readers to understand the chronology of the therapeutic steps needed for CLP treatment, we shall present an outline of the gamut of procedures that identifies all the phases and intervention times (table 1) taking the indispensable biological principles that encourage normal facial growth, and well func- tioning ventilation, mastication, and phonation in account. This schedule will, we believe, help readers gain a good understanding of the objectives, the techniques, and the chronology of the successive phases of therapy without going into details about particular techniques that may be specific to individual treatment centers.

\section{3 - INITIAL MORPHO-FACIAL REHABILITATION}

A critical first surgical step is closing the soft palate gap, rehabilitating the labial and nasal defects, and bringing the edges of the osseous hard palate cleft closer together. Because semiclosure does not stimulate formation of the missing bone, caregivers must find other means of re-establishing function and promoting facial growth. The modalities of installing a graft are still in question. What type should it be? When should it be placed? Today, most treatment teams agree that repair of the cleft should be early and global. In their protocol for a single surgical procedure Stricker et al. ${ }^{13}$ and 


\begin{tabular}{|c|c|c|c|}
\hline Therapeutic stage & Objective & Method & Timing \\
\hline 1. Pre-operative & - Diagnosis & - Information & -> Prenatal \\
\hline $\begin{array}{l}\text { 2. Initial morpho-functional } \\
\text { rehabilitation }\end{array}$ & $\begin{array}{l}\text { - Restore a morphology fa- } \\
\text { vorable to proper func- } \\
\text { tioning }\end{array}$ & $\begin{array}{l}\text { - Cheïlo-urano-staphylorraphic } \\
\text { reconstruction } \\
\text { - Potential morphogenetic graft } \\
\text { (early periosteal or later oss- } \\
\text { eous) }\end{array}$ & $\begin{array}{l}->\text { From } 6 \text { months to } 5 \\
\text { years }\end{array}$ \\
\hline $\begin{array}{l}\text { 3. Orthophonic } \\
\text { rehabilitation }\end{array}$ & $\begin{array}{l}\text { - Enhance articulate utter- } \\
\text { ance }\end{array}$ & $\begin{array}{l}\text { - Orthophonics } \\
\text { - Pharyngoplasty (if necessary) }\end{array}$ & $\begin{array}{l}->\text { From } 2 \text { years } \\
->\text { Before } 6 \text { years }\end{array}$ \\
\hline $\begin{array}{l}\text { 4. Orthodontic } \\
\text { rehabilitation }\end{array}$ & $\begin{array}{l}\text { - Surgical and orthodontic } \\
\text { (as needed for residual } \\
\text { morphological defects) }\end{array}$ & $\begin{array}{l}\text { - Dento-maxillary orthopedics } \\
\text { - Orthodontics }\end{array}$ & $->$ End of growth period \\
\hline $\begin{array}{l}\text { 6. Dental } \\
\text { rehabilitation }\end{array}$ & $\begin{array}{l}\text { - Esthetic and functional } \\
\text { repair of masticatory sys- } \\
\text { tem }\end{array}$ & $\begin{array}{l}\text { - Periodontics, } \\
\text { - Eventual pre-prosthetic } \\
\text { orthodontics }\end{array}$ & $->$ End of growth period \\
\hline $\begin{array}{l}\text { 7. Esthetic } \\
\text { rehabilitation }\end{array}$ & $\begin{array}{l}\text { - Ultimate corrections to } \\
\text { establish facial harmony }\end{array}$ & - Esthetic nasal and lip surgery, & -> Growth completed \\
\hline
\end{tabular}

Table 1

CLP rehabilitation stages schedule.

Simon et al. ${ }^{12}$ suggested that surgeons should use a periosteal tibial graft placed lengthwise to cover the alveolar crest as well as the palate in order to take advantage of the osteogenic capacities of the periosteum. To do so they propose the construction of a bone bridge to establish continuity between the fragments. In this protocol, after a stage of early orthopedic treatment with a fixed "Latham" type appliance whose goal is to align the fragments correctly, surgeons may at the same time also perform a gingivoperiosteoplasy. With this therapeutic approach surgeons can repair the nose using only nasal tissue, backing up the external mucosa with the abundant and resistant palatal mucosa and repairing the oral area without using palatal fibro-mucosa, thus avoiding the possibility of scar tissue eventually interfering with maxillary expansion ${ }^{12}$.

Talmant and Lumineau ${ }^{14}$ recommend this surgical algorithm: after closure of the soft palate, correction of the labio-nasal base at 6 months, closure of the hard palate at 18 months, repositioning of the fragments with a quad helix after patients reach 3 and a half years of age, before performing a gingivo-periostoplasty with an iliac bone graft on 4 to 5 year-old patients. 
Other teams suggest secondary bone graft placement at a relatively early teething stage, that is during eruption of permanent teeth, concomitant with orthodontic treatment. According to proponents of this view ${ }^{4,5}$, early bone grafts facilitate migration of permanent canine teeth through them and stabilize teeth adjacent to the cleft. But this notion seems less sound when the conditions of the graft survival depend on the frequent agenesis of upper lateral incisors and on the ability of the canine to drift through the graft are considered ${ }^{9}$.

\section{4 - DENTO-FACIAL ORTHOPEDICS}

Most of the problems that cleft palate patients experience in their mixed dentitions are not directly related to the cleft itself but are associated with the early surgery. Even though this procedure may have provided notable improvements the lip closure might have caused pressures that limited forward maxillary growth and closure of the palatal cleft might have constricted the transverse width of upper canine and premolar sectors. Of course these early surgical interventions are fully justified by the esthetic and functional benefits they confer but their unacceptable side effects make dentofacial orthopedic and orthodontic treatment in the mixed dentition an important component of the rehabilitation of CLP patients.

Orthodontic management of CLP patients, which had not previously been indicated, becomes imperative when upper incisors erupt ${ }^{10}$ because these teeth frequently enter the arch rotated, lingually inclined, or in lingual cross bite.
A retrospective study conducted in the three treatment centers with different surgical protocols ${ }^{3}$ showed that 9 and 12 year-old patients had similar inter-arch relationships. The authors concluded that neither postponing closure of the palate nor undertaking early orthopedic treatment conferred any long-term benefits.

But the early osteotomies of the pre-maxilla that one of the centers performed seemed to cause less favorable inter-arch relationships.

Cross bites of the buccal teeth are also not uncommon because of the cleft's interference with normal transverse growth. The first step of orthodontic therapy is correction of these posterior discrepancies.

CLP patients usually suffer two postoperative anatomical complications. First, the morpho-functional surgical rehabilitation leaves palatal mucosal adhesions, and secondly treated patients do not have the normal medial palatal suture, leaving them with palates narrower than normal.

Because of the absence of the midline suture, rapid palatal expansion is not indicated and orthodontists use quad helix appliances instead ${ }^{10}$. But even this slower expansion procedure may provoke enough palatal mucosal tension to reveal or enlarge pre-existing fistulas that maxillo-facial surgeons must correct in a secondary intervention ${ }^{8}$.

Another objective of orthopedic treatment for CLP patients is to correct retruded maxillas as much as possible. The primary means ortho- 
dontists have available for this enterprise include Delaire type extra-oral protraction masks and fixed appliances capable of operating Class III mechanics. Today, orthodontists prefer to use the intra-oral Class III mechanics approach because it does not provoke the counter clockwise rotation sometimes caused by facemask therapy ${ }^{1}$. Another advantage of this full-banded therapy is its capacity to align incisor teeth, to control torque, and to correct the palatal inclination of upper incisor teeth that has caused anterior cross bite.

\section{5 - ORTHODONTICS}

When the permanent dentition is fully in place, the primary objective for orthodontists is to correct antero-posterior and transverse occlusal relationships between the two dental arches of CLP patients with a full-banded and bonded appliance without removing any permanent teeth in order to obtain the fullest arch form that will lend needed support to their lips.

Working in collaboration with maxillo-facial surgeons, orthodontists will at this time bring any unerupted or impacted permanent teeth into their proper arch positions. During the full period of full appliance treatment, orthodontists must insist that CLP patients maintain scrupulously good oral hygiene, assisted by prophylaxis when indicated, because studies have shown the prevalence of decay is higher for them than it is for control groups ${ }^{5}$.

Cleft palate patients frequently have congenitally absent teeth, especially
Soon more orthodontists will be using mini-plates anchored in bone as an anchorage source for deriving force to correct retruded maxillas instead of teeth in the dental arch. Baek et al. ${ }^{2}$ used implanted plates instead of traditional tooth-borne anchorage to treat 3 cleft palate patients, noting that this procedure eliminated the extrusion of anchorage teeth and caused a minimum of other unwanted side effects such as posterior mandibular rotation and opening of the occlusion.

upper lateral incisors, and occasionally a doubling of these teeth, one on each side of the cleft. In fact $40 \%$ of CLP patients are missing maxillary lateral incisors, usually on the side of the cleft $^{1,7,14}$. So when orthodontists are establishing their treatment plans for these children they should make a careful assessment of residual spaces in the dental arch to determine if the child has missing or doubled maxillary lateral incisors. Extractions of these teeth, or of unneeded supernumeraries, should be delayed as long as possible because in erupting they bring with them precious alveolar bone.

When an upper lateral is absent or severely undersized, orthodontists have to decide whether to close the space by moving the canine into the lateral region and mesialize the buccal segment or to maintain the space for an eventual implant or bridge, thus leaving posterior teeth in normal 
occlusion. As is the case for all instances of congenitally absent teeth, there is no ideal solution. If treatment teams decide to preserve the space, as most do today, they will be increasing the width of the premaxilla needed for the permeability and the nasal ventilation that are indispensable elements of maintenance of transverse dimension ${ }^{15,16}$. But if they close the space they increase the risk of development of a retruded maxilla that will complicate orthodontic treatment and make the need more likely for orthognathic surgery at the end of the growth period. So closing spaces left by congenitally absent maxillary lateral incisors should be reserved only for patients whose dentitions are severely crowded. Because we believe that in most cases missing laterals should be replaced prosthetically or with implants, we form our orthodontic treatment plans to take this principle into account.

Retention for treated CLP patients is critical. Unless it is continued for the long term, relapse is likely ${ }^{1}$. We recommend the use of fixed, bonded anterior retainers that run from a tooth on one side of the former cleft to a tooth on the other side in association with a removable night time retainer or a permanent one designed to maintain the expanded transverse dimension.

\section{6 - REHABILITATION OF SEQUELLAE OF CLEFTS}

If the initial intervention of the treatment team has worked out as planned, only one of ten CLP patients will later require orthognathic surgery ${ }^{11}$. The residual problems that they will have will be primarily maxillary and mandibular skeletal discrepancies and esthetic facial deficiencies that can be corrected surgically and/or orthodontically after the growth period has ended.

The anterior teeth of patients whose face is characterized by a major growth differential between maxilla and mandible are more likely to suffer relapse into cross bite than those of patients whose jaw growth is relatively harmonious ${ }^{4}$. This complication does not necessarily result from excessive mandibular growth but is more frequently caused by a sagittal maxillary deficit caused by the braking action of scar tissue associated with surgical reconstruction of the upper lip ${ }^{4}$.

The quality of the initial morphofunctional rehabilitation is crucial. An exhaustive study conducted in different qualified treatment centers ${ }^{3,6}$ has shown that the rate of eventual orthognathic surgery varies from team to team.

Sometimes surgeons need to install a later secondary facial graft to create a pseudo-osteoarthritic formation in the premaxilla as an indispensable pre-condition for an osteotomy ${ }^{9}$. The timing for orthognathic surgery is particularly important. Before operating, surgeons must ascertain that the patient's growth curve of osseous maturity has been reached, which 
may be attained by girls at the age of 16. But the end of facial growth never occurs in boys before the age of 19 .

As in all orthognathic surgery, the operative objective in CLP interventions is to place both dental arches in correct positions and in correct relationship with each other. To assure achievement of good dento-alveolar compensations, this surgery should never be accompanied by extraction of permanent teeth. And when CLP patients have thin and tight lips, maxillary protrusion never develops ${ }^{4}$.

With these patients, the osteotomy consists accordingly of maxillary advancement but in some cases, when, for example, mandibular prognathism is present, the surgeon will operate on both jaws. But sometimes the possibilities of surgical maxillary advancement are limited by the eventual adverse consequences it might have on phonation. If the gap in the anterior

\section{7 - CONCLUSION}

Teams caring for CLP patients must take into account the severity of the deformities to be corrected and their stages of development when multidisciplinary treatment plans are formulated for rehabilitation of patients' faces. These programs, of course, must conform to the rehabilitation process that surgeons and their coworkers are the first to implement.

Orthodontists employ standard techniques in treating these children that remain relatively independent of the various surgical protocols that have been employed and in dealing with CLP patients confront all the cross bite is greater than $8 \mathrm{~mm}$ with a deficit limited to the maxilla, a bimaxillary surgical intervention will be necessary even if it is not justified from an esthetic point of view ${ }^{4}$. Surgeons should create a moderate over-correction of the anterior cross bite in order to compensate for the effects of an anticipated relapse.

Post-surgical orthodontic treatment as in classical surgico-orthodontics emphasizes achievement of good inter-cuspidation with the aid of vertical elastics. Once good sagittal relationships have been obtained dentists can improve gingival crestal morphology and create conditions adapted to the prosthetic or implant replacement of missing teeth with periodontal surgery. Then surgeons can begin esthetic reshaping of the lips and nose, procedures that often embody the patient's most highly desired sites for improvement.

same biological constraints that they are accustomed to working under in their regular daily practices. The orthodontic mechanics needed to treat CLP patients are few in number and routine in nature.

All orthodontists who have demonstrated their understanding of the general organization of procedures common to the treatment of clefts, thanks to their training qualifications have the competence to undertake successfully the orthodontic care of CLP patients. Their contributions earn a place in "the grand therapeutic schedule" where the objectives of 
the phases of CLP rehabilitation, the means for accomplishing them, and the results anticipated are inscribed.

In this article we have expressed our belief that orthodontists are important participants in the team that undertakes the treatment of CLP patients, possessing all the knowledge and skills needed for the group's essential coordination, cooperation, and communication.

\section{REFERENCES}

1. Aknin JJ. Le point sur les fentes labio-alvéolo-palatines. Rev Orthop Dento Faciale 2008;42:391-402.

2. Baek SH, Kim KW, Choi JY. New treatment modality for maxillary hypoplasia in cleft patients. Protraction facemask with miniplaque anchorage. Angle Orthod 2010;80:595-603.

3. Bartzella T, Katsaros C, Shaw WC et al. A longitudinal three-center study of dental arch relationship in patients with bilateral cleft lip and palate. Cleft Palate Craniofac J 2010; 47:167-74.

4. Bayley L'TJ, Sarver DM, Turvey TA, Proffit WR. Class III problems. In: Proffit WR, White RP Jr, Sarver DM eds. Contemporary treatment of facial deformity. St Louis: Mosby 2003:543-55.

5. Britton KF, Welbury RR. Dental caries prevalence in children with cleft lip/palate aged between 6 months and 6 years in West of Scottland. Eur Arch Pediatr Dent 2010;11:236-41.

6. Broome M, Herzog G, Hohlfeld J, de Buys Roessingh A, Jaques B. Influence of the primary cleft palate closure on the future need for orthognathic surgery in unilateral cleft lip and palate patients. J Cranio-fac Surg 2010;21(5):1615-18.

7. Camporesi M, Baccetti T, Marinella A, Defraia E, Franchi L. Maxillary dental anomalies in children with cleft lip and palate : a controlled study. Int J Paediatr Dent 2010;20(6):442-50.

8. Lesne V. Le traitement orthodontique de l'enfant porteur de fente. Orthod $\mathrm{Fr}$ 2004;75:321-38.

9. Morand B, Durouvre F, Raphael B. Le déficit osseux des fentes labiomaxillo-palatines: revue des procédés Expérience de greffe périostée tibiale. Orthod Fr 2004;75:217-28.

10. Proffit WR, Fields HR Jr. Contemporary Orthodontics $3^{\text {rd }}$ ed. St Louis: Mosby, 2000:240-94.

11. Shaw WC et al. A six-center national study of treatment outcome in patients with clefts of lip and palate. Part 5. General discussion and conclusions. Cleft Palate Craniofac J 1992.29:413-18.

12. Simon E, Durour F, Coing C, Sellal S, Chassagne J-F, Stricker M. Principes de prise en charge des fentes labio-maxillo-palatines unilatérales totales Propositions de protocole. Orthod Fr 2004;75:229-41.

13. Stricker M, Chancholle AR, Flot F, Malka G, Montoya A. La greffe périostée dans la réparation de la fente totale du palais primaire. Ann Chir Plast 1977;22:117-25.

14. Talmant JC, Lumineau J-P. Approches thérapeutiques des fentes labio-maxillopalatines : pour une croissance faciale normale Un protocole et des techniques au service de la ventilation nasale. Orthod Fr 2004;75:297-319.

15. Talmant J, Talmant J-C, Deniaud J. Mécanique de l'enveloppe faciale : 2 . Fente orale et concentration des contraintes (aspects fondamentaux). Rev Orthop Dento Faciale 1999;33:211-32.

16. Talmant J, Deniaud J, Nivet MH. Définition de la "ventilation nasale optimale». In : La dimension verticale. $1^{\text {re }}$ partie, Ventilation nasale et dimension verticale. Orthod $\mathrm{Fr}$ 2003;74:201-25. 